\title{
Validation of a new technique to detect Cryptosporidium spp. oocysts in bovine feces
}

\author{
Sandra Valéria Inácio ${ }^{a}$,*, Jancarlo Ferreira Gomes ${ }^{\mathrm{b}}$, Bruno César Miranda Oliveira ${ }^{\mathrm{a}}$, \\ Alexandre Xavier Falcão ${ }^{c}$, Celso Tetsuo Nagase Suzuki ${ }^{c}$, Bianca Martins dos Santos ${ }^{\mathrm{d}}$, \\ Monally Conceição Costa de Aquino ${ }^{a}$, Rafaela Silva de Paula Ribeiro ${ }^{a}$, \\ Danilla Mendes de Assunção ${ }^{a}$, Pamella Almeida Freire Casemiro ${ }^{a}$, \\ Marcelo Vasconcelos Meireles $^{\text {a }}$, Katia Denise Saraiva Bresciani ${ }^{\text {a }}$ \\ a UNESP - Universidade Estadual Paulista Júlio de Mesquita Filho, Departamento de Apoio, Produção e Saúde Animal, Faculdade de Medicina Veterinária de \\ Araçatuba, Araçatuba, São Paulo, Brazil \\ b UNICAMP, Universidade Estadual de Campinas, Institutos de Biologia e Computação, Campinas, São Paulo, Brazil \\ c UNICAMP, Universidade Estadual de Campinas, Instituto de Computação, Campinas, São Paulo, Brazil \\ d UNICAMP, Universidade Estadual de Campinas, Instituto de Biologia, Campinas, São Paulo, Brazil
}

\section{A R T I C L E I N F O}

\section{Article history:}

Received 4 February 2016

Received in revised form 15 August 2016

Accepted 23 September 2016

\section{Keywords:}

Parasites

Coccidiosis

Diagnostic

\begin{abstract}
A B S T R A C T
Due to its important zoonotic potential, cryptosporidiosis arouses strong interest in the scientific community, because, it was initially considered a rare and opportunistic disease. The parasitological diagnosis of the causative agent of this disease, the protozoan Cryptosporidium spp., requires the use of specific techniques of concentration and permanent staining, which are laborious and costly, and are difficult to use in routine laboratory tests. In view of the above, we conducted the feasibility, development, evaluation and intralaboratory validation of a new parasitological technique for analysis in optical microscopy of Cryptosporidium spp. oocysts, called TF-Test Coccidia, using fecal samples from calves from the city of Araçatuba, São Paulo. To confirm the aforementioned parasite and prove the diagnostic efficiency of the new technique, we used two established methodologies in the scientific literature: parasite concentration by centrifugal sedimentation and negative staining with malachite green (CSN-Malachite) and Nested-PCR. We observed good effectiveness of the TF-Test Coccidia technique, being statistically equivalent to CSN-Malachite. Thus, we verified the effectiveness of the TF-Test Coccidia parasitological technique for the detection of Cryptosporidium spp. oocysts and observed good concentration and morphology of the parasite, with a low amount of debris in the fecal smear.
\end{abstract}

(c) 2016 Elsevier B.V. All rights reserved.

\footnotetext{
* Corresponding author at: Departamento de Apoio, Produção e Saúde Animal, Faculdade de Medicina Veterinária de Araçatuba, Universidade Estadual Paulista UNESP, Rua Clóvis Pestana, 793, Jardim D. Amélia, CEP 16050-680, Araçatuba, SP, Brasil.

E-mail addresses: sandra_byol@yahoo.com.br (S.V. Inácio), jgomes@ic.unicamp.br (J.F. Gomes), bruno.9988@hotmail.com (B.C.M. Oliveira), afalcao@ic.unicamp.br (A.X. Falcão), celso.suzuki@gmail.com (C.T.N. Suzuki), biancamsantos@yahoo.com.br (B.M. dos Santos), monallyaquino@yahoo.com.br (M.C.C. de Aquino), rafaela.ribeiro123@hotmail.com (R.S. de Paula Ribeiro), danilla.assuncao@hotmail.com (D.M. de Assunção), pamellacasemiro@hotmail.com (P.A.F. Casemiro), marcelo@fmva.unesp.br (M.V. Meireles), bresciani@fmva.unesp.br (K.D.S. Bresciani).
}

\section{Introduction}

Being an important zoonotic pathogen, Cryptosporidium spp. infects mammals, birds, reptiles, amphibians and fish (Fayer, 2010; Xiao, 2010). This parasite causes diarrhea in calves (Vargas et al., 2014), with growth retardation, mortality and consequent economic loss (Olson et al., 2004; Santín et al., 2008). In cattle, the most common species are Cryptosporidium parvum (Santín et al., 2008), Cryptosporidium ryanae, Cryptosporidium andersoni (Xiao, 2010) and Cryptosporidium bovis (Feng et al., 2007; Fayer et al., 2008; Rieux et al., 2013).

Laboratory diagnosis of Cryptosporidium oocysts in feces can be performed by means of parasite concentration techniques followed by the use of specific and permanent stains as Ziehl-Neelsen (Henriksen and Pohlenz, 1981), Kinyoun (Lennette et al., 1985), 
negative malachite green staining (Elliot et al., 1999), safranin methylene blue (Garcia, 2007, 2009) and trichrome (Garcia, 2007, 2009). Other techniques can also be used for this diagnostic purpose, such as phase contrast microscopy (Teixeira et al., 2011), direct fluorescent antibody test (CDC, 2015) and enzyme-linked immunosorbent assay (CDC, 2015).

Nowadays, the laboratory diagnosis of Cryptosporidium spp. oocysts requires the use of specific concentration and permanent staining techniques, which are labor-intensive and costly, and have difficulty in its implementation in the routine of a clinical laboratory (Gomes et al., 2004; Garcia, 2007; Carvalho et al., 2012, 2016).

The precursor technique of this study, called TF-Test (Three Fecal Test), has been used with practicality for years for fecal parasitological diagnosis in humans, with excellent results (Gomes et al., 2004; Carvalho et al., 2012, 2016). More recently, this technique has been extended to research in animal area by studies involving sheep (Lumina et al., 2006) and canine (Coelho et al., 2013, 2015) species. In these works, new diagnostic procedures were validated with gastrointestinal helminths and protozoa, not taking into account the genus Cryptosporidium.

In view of the above, continuing the line of research regarding the above technique, we analysed the feasibility, development, evaluation and intralaboratory validation of a new and practical parasitological technique for analysis in optical microscopy of Cryptosporidium spp. oocysts, called TF-Test Coccidia (Fig. 3), using fecal samples from calves from the city of Araçatuba, São Paulo.

\section{Material and methods}

This study was approved by the Animal Ethics Committee of the Faculdade de Odontologia do Campus de Araçatuba - UNESP, with protocol number 2013-00847.

\subsection{Harvest and storage of fecal samples}

Considering the irregular shedding of oocysts of Cryptosporidium spp. (Garcia, 2007, 2009; CDC, 2015), fecal samples were harvested (collected) on three alternate days, directly from the rectum of each calf. This material was divided into three parts: the first part $50 \mathrm{~mL}$ was stored under refrigeration for use in the parasite concentration technique by centrifugal sedimentation and negative staining with malachite green, named in our study as CSN-Malachite; the second part (5.4 g) was kept in the collecting tubes of TF-Test Coccidia; and the third 200 milligrams part was kept frozen at $-20^{\circ} \mathrm{C}$ until the time of genomic DNA extraction and nested polymerase chain reaction (nested $P C R$ ).

\subsection{Processing of fecal samples}

For the confirmation of oocysts and statistical comparison of techniques, besides the new TF-Test Coccidia technique, we used two established techniques in the scientific literature: nested PCR (confirmation of oocysts) and CSN-Malachite (statistical comparison), respectively.

\section{Experimental design}

\subsection{Protocol standardization of the new technique}

\subsubsection{Study description}

This intralaboratory study was conducted with the support of a farm of dairy cattle breeding in the city of Araçatuba, São Paulo, identified with positive samples, during the period of March 2014. For this step, fecal samples ( $n=60$ ) were processed only by the $C S N$ Malachite technique. As a result, we obtained five positive samples for Cryptosporidium spp. oocysts, which were later divided into 100 aliquots for the development and standardization of the operating protocol of the TF-Test Coccidia technique. A total of 60 Holstein calves, 11 males and 49 females, aged from six to 480 days, were involved in this study.

\subsection{New technique validation}

\subsubsection{Study description}

This intralaboratory research was conducted with fecal samples in 10 dairy cattle breeding farms in the city of Araçatuba, São Paulo, during the period from March 2014 to October 2015. For this step, we used the CSN-Malachite technique to perform the screening of samples to assess the occurrence of Cryptosporidium spp. oocysts in the fecal content of cattle. After this screening, we applied the standard protocol of the new TF-Test Coccidia diagnostic technique. The diagnostic of fecal samples were confirmed by nested PCR. Lastly, a total of 68 calves of Holstein and Girolanda races, 15 males and 53 females, aged between one and 540 days, were examined to assess the presence of the parasite, resulting in 34 positive samples and 34 negative samples for intralaboratory evaluation. These animals were classified according to their age in two groups: $\leq 30$ days and $\geq 31$ days.

\subsection{Centrifugal sedimentation with negative malachite green stain modified technique (CSN-Malachite)}

For this procedure, we obtained a pool of three samples for each animal. This material was processed in the laboratory in accordance with the literature of centrifugal sedimentation (Meloni and Thompson, 1996) and staining with malachite green (Elliot et al., 1999).

\subsubsection{New TF-Test coccidia technique}

This technique consisted of the following steps:

The three collection tubes (Fig. 3) of TF-Test Coccidia (containing formalin) containing $5.4 \mathrm{~g}$ of the collected feces were placed in an appropriate shelf. In this material, $25 \mu \mathrm{L}$ of surfactant organic solvent (colorless neutral detergent) and $3 \mathrm{~mL}$ of ethyl acetate pro analysis (Formula $\mathrm{C}_{4} \mathrm{H}_{8} \mathrm{O}_{2}$ ) were added to each tube. Then, the respective tubes with their caps were closed and shaken vigorously for $30 \mathrm{~s}$ with a vortex mixer. After that, the caps of the tubes were removed and connected to the other two parts, called set of filters and centrifuge tube. The union of all these parts was denominated in this study "set processor". Subsequently, this set was centrifuged for two minutes at $500 \times \mathrm{G}$ (gravitational force). After this centrifugation, the centrifuge tube was disengaged from the set of filters and collection tubes. Next, the supernatant liquid was decanted from the centrifuge tube, so leaving $500 \mu \mathrm{L}$ of sediment in the conical bottom of the centrifugation tube. In this sediment, $250 \mu \mathrm{L}$ of treated water were added and mixed, providing the formation of a fecal suspension. This suspension was redeemed using an automatic pipette, and $150 \mathrm{~mL}$ of the fecal suspension were transferred to a TF-Test Coccidia collection tube. Then a drop of colorless neutral detergent was added to this material and the whole suspension was manually mixed. After that, $3 \mathrm{~mL}$ of neutral formalin solution were added to this material and all material was mixed vigorously for $30 \mathrm{~s}$ with a vortex mixer. In sequence, $3 \mathrm{~mL}$ of ethyl acetate pro analysis were added, and all material was shaken again for another 30 s on the vortex mixer. Then, the tube was centrifuged at $333 x$ $\mathrm{G}$ for one minute. After this centrifugation, the supernatant was decanted using a pipette, until a small aliquot of suspension on the bottom of the demarcated tube was left, and $25 \mu \mathrm{L}$ of this material were transferred to a microscope slide. Then, on the slide, $25 \mu \mathrm{L}$ of the dye developed and standardized in the study $(25 \mu \mathrm{L}$ of modified D'Antoni's iodine solution and $50 \mu \mathrm{L}$ of modified Masson's 
trichrome) were added. Finally, a fecal smear was made on the slide and a coverslip was superimposed for examination by optical microscopy.

\subsubsection{Staining and microscopy}

The operational protocol of the new technique allowed, even with samples fixed with neutral formalin solution, the preparation of fecal smear using temporary staining composed of modified D'Antoni's iodine solution and modified Masson's trichrome. This new dye allowed the reading of a microscope slide with dry objective lens of $60 \mathrm{x}$ and $100 \mathrm{x}$ magnification in a conventional optical microscope, without the need for immersion oil. It is worth mentioning that these objective lenses for use without immersion oil have good image quality and were recently introduced in the market by Olympus industry, with the following descriptions: objective lens $60 \mathrm{x}$ - UPlan FLN and objective lens $100 \mathrm{x}$ - Plan FLN.

\subsection{Nested PCR targeting the 18 S ribosomal RNA gene of Cryptosporidium spp}

\subsubsection{Fecal DNA extraction}

The DNA was extracted from $200 \mathrm{mg}$ of 68 fecal samples "in natura", stored at $-20^{\circ} \mathrm{C}$ until genomic DNA extraction; for the extraction of samples it was performed heating to $99^{\circ} \mathrm{C}$ for $60 \mathrm{~min}$ for breaking the wall of the oocyst, using QIAamp ${ }^{\circledR}$ DNA Stool Mini Kit (Qiagen ${ }^{\circledR}$ ). The DNA was eluted with $50 \mu \mathrm{L}$ AE buffer and stored at $-20^{\circ} \mathrm{C}$.

\subsubsection{Nested PCR}

Nested PCR was performed for amplification of a fragment of the 18 S ribosomal RNA gene (Xiao et al., 2000). Cryptosporidium parvum DNA was used as positive control and ultrapure water was included as a negative control, followed by electrophoresis from a $1.5 \%$ agarose gel.

For amplification of the $18 \mathrm{~S}$ subunit ribosomal RNA gene fragments it was used nested PCR with primers from Sigma-Aldrich ${ }^{\circledR}$ 5 'TTC AGC TAG TAA ATG TAC CG 3 ' and 5 'CCC ATT ACA GGA TCC GAA TTC 3 'for the primary reaction, with 1325 base pairs (bp) and 5'-AGG GTT GGA GTA TTT ATT AGA AAT GA 3' and 5 'AAT GGA AAG GAG ACC ACA TCC 3 ' for the secondary reaction (bp 826-840). To perform the following reaction conditions, there was prepared a solution with a final volume of $25 \mu \mathrm{L}$ from JumpStart Taq ${ }^{\mathrm{TM}}$ READYMIX $^{\mathrm{TM}}$ reagent from Sigma-Aldrich ${ }^{\circledR}$, for primary reaction was used: JumpStart Taq ${ }^{\mathrm{TM}} \mathrm{READYMIX}^{\mathrm{TM}} 12.5 \mu \mathrm{L}$, primer $10.5 \mu \mathrm{L}$, primer $20.5 \mu \mathrm{L}, \mathrm{H}_{2} \mathrm{O} 8.25 \mu \mathrm{L}$, BSA $0.75 \mu \mathrm{L}$ and DNA target $2.5 \mu \mathrm{L}$. To use secondary reaction: JumpStart Taq ${ }^{\mathrm{TM}}$ READYMIX $^{\mathrm{TM}} 12.5 \mu \mathrm{L}$, primer $30.5 \mu \mathrm{L}$, primer $40.5 \mu \mathrm{L}, \mathrm{H}_{2} \mathrm{O} 9.0 \mu \mathrm{L}$ and DNA target $2.5 \mu \mathrm{L}$. The samples were subjected to DNA initial denaturation at $94{ }^{\circ} \mathrm{C}$ for $3 \mathrm{~min}$ followed by 34 cycles each consisting of denaturation for $45 \mathrm{~s}$ at $94^{\circ} \mathrm{C}, 45 \mathrm{~s}$ annealing at $55^{\circ} \mathrm{C}$ and $60 \mathrm{~s}$ extension at $72{ }^{\circ} \mathrm{C}$ with extension end at $72^{\circ} \mathrm{C}$ for $7 \mathrm{~min}$ (Xiao et al., 2000).

\subsection{Statistical analysis}

The variables (sex, breed and age) were analysed by the chisquare test $(\chi 2)$ or Fisher's exact test for the association between the variables.

The Kappa statistic was used to measure the agreement between the mentioned techniques.

We used the SAS software (SAS, 2015) for the statistical calculations, with 5\% significance level.

\section{Results}

In the intralaboratory study of the new TF-Test Coccidia technique, we observed good sharpness and morphology of oocysts of

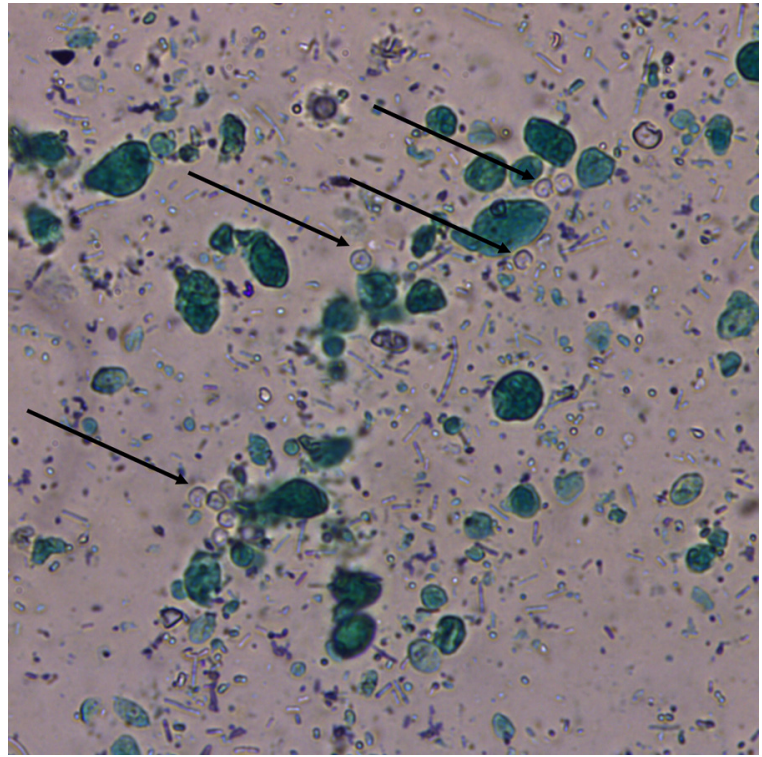

Fig. 1. Image of Cryptosporidium spp. oocysts in a sample of calf feces, with the use of a dry objective lens with $60 \mathrm{x}$ magnification.

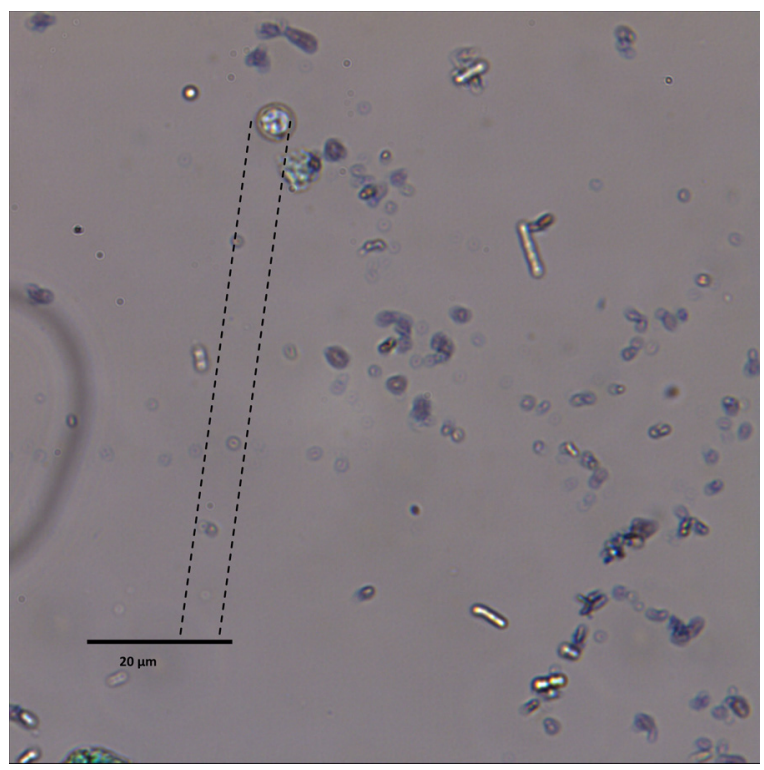

Fig. 2. Image of Cryptosporidium spp. oocyst in a sample of calf feces, with the use of a dry objective lens with $100 \mathrm{x}$ magnification.

Cryptosporidium spp. (Figs. 1 and 2). The same could not be demonstrated in most slides processed by the CSN-Malachite technique, in accordance with literature reports (Coelho et al., 2015).

Furthermore, the new technique presented fecal smear slides with low quantity of debris, good concentration of parasite on a microscope slide (Fig. 1) and demonstrated the preparation of fecal smears with the use of a new temporary stain. Unlike conventional staining, the dye of the new technique allowed to highlight the sporozoites of oocysts with a purple hue (Fig. 2), and the fecal debris with a green color.

The concentration adjustment between an iodine solution and Masson allowed this new composition dye work with same accuracy in fecal samples collected in neutral formalin solution, unlike literature indications (Garcia, 2007, 2009).

In this intralaboratory study, the same examiner detected 34 positive samples in 68 calves examined by both CSN-Malachite and 


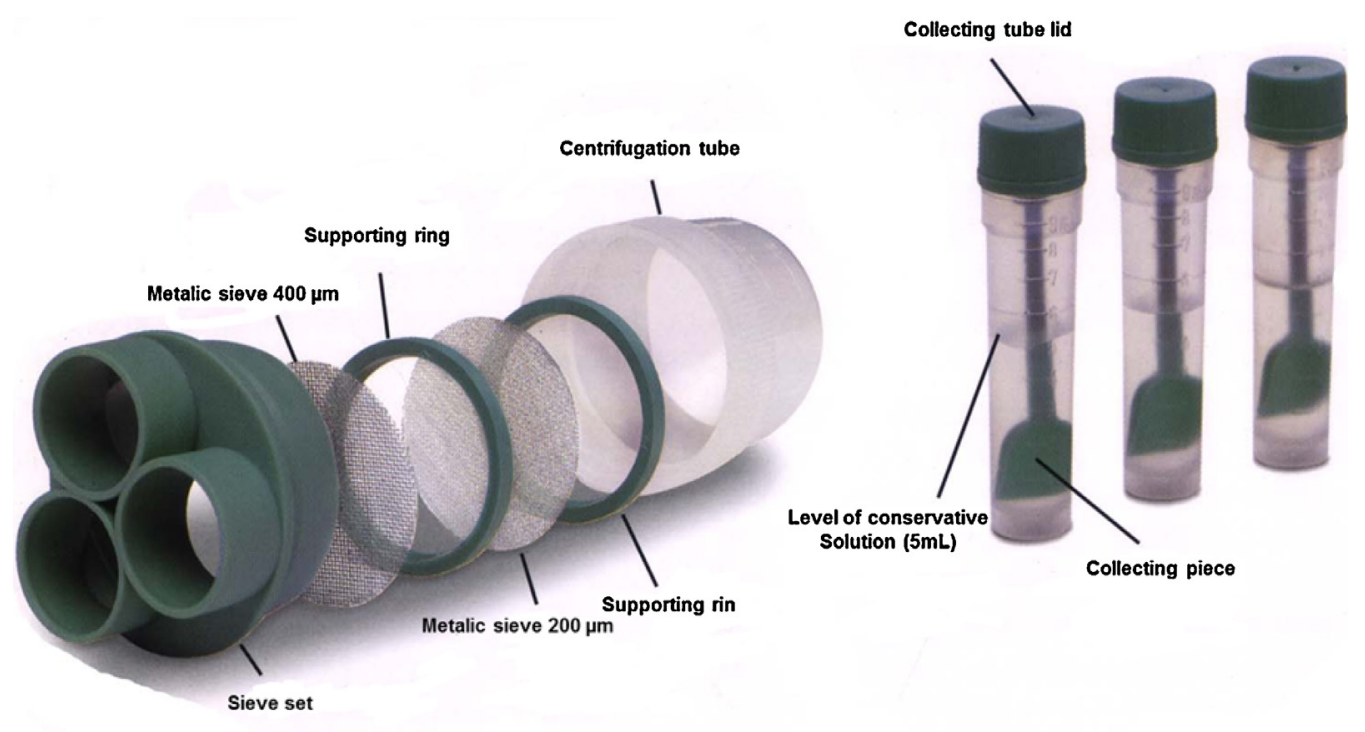

(A)

Fig. 3. Illustration of the set of centrifugation (A) and collectors tubes (B) of TF-Test Coccidia.

TF-Test Coccidia techniques, with full statistical correlation between these results $($ Kappa $=1.000)$. However, with nested-PCR we confirmed 24 positive and 10 false negative samples.

Regarding the negative samples $(n=34)$, there are statistic agreement between the CSN-Malachite and TF-Test Coccidia and nested $P C R$ techniques.

By the chi-square test $(\chi 2)$, a higher frequency of infection by Cryptosporidium spp. was observed in younger calves in relation to other age groups $(\mathrm{P}<0.0001)$, and with respect to sex and breed, there was no significant difference in parasitic infection rate $(\mathrm{P}>0.05)$.

\section{Discussion}

Through the data shown in this intralaboratory study, we observed good efficacy in oocyst detection of the protozoan Cryptosporidium spp. by using the TF-Test Coccidia technique, which favors the use of this new technique in laboratory routine.

For this research, we prefer to take fecal samples of newborn calves (Fayer and Santín, 2009; Silverlås et al., 2010) because they present higher frequency of cryptosporidial infection, which was confirmed by our results that showed a significant difference for this age group compared to animals of other ages.

The new technique clearly showed fecal smears with good parasitic concentration, and largely free of debris (Figs. 1 and 2). In many slides it was possible to view a concentration of more than seven oocysts per field, with $60 \mathrm{x}$ magnification objective lens without immersion (Fig. 1). This should favor the detection of oocysts of this parasite in microscope reading practiced in laboratory routine, reducing fatigue and diagnostic interpretation error practiced by humans.

The use of the new dye preserved the morphological integrity of Cryptosporidium spp. oocysts, always dyeing the sporozoites in lilac color (Fig. 2) and almost all of the impurities in green. This condition should facilitate the microscopy reading, significantly reducing the diagnostic interpretation error practiced by humans, which can occur with a false positive or false negative result.

Unlike literature recommendation (Garcia, 2007, 2009), the TFTest Coccidia technique allowed the preparation of slides with temporary coloring and microscopy reading with dry objective lens. This eliminated the limitations provided by specific tech- niques using permanent dyes, for example, those derived from carbol fuchsin, which despite demonstrating excellent diagnostic performance, are rarely used in routine laboratory because they are labor-intensive and costly.

For the CSN-Malachite and TF-test Coccidia techniques, the results were concordant for the presence of the protozoan Cryptosporidium spp., that is, the same animals showed positive $(\mathrm{n}=34)$ and negative $(\mathrm{n}=34)$ samples. PCR was used only for confirmation of fecal samples, to indicate that TF-Test Coccidia detected the oocysts in the samples correctly.

The same examiner performed the processing of stool samples with the negative staining with malachite green (CSN-Malachite) and TF-Test Coccidia techniques, which were later confirmed by Nested PCR. The samples were processed randomly in each technique, without a sort order for the reading of the fecal samples, and thus the examiner was not suggestible when interpreting the data.

The proper selection of an extraction and purification method is crucial to ensure reliable results (Paulos et al., 2016), and is widely known that molecules found in fecal samples, or in the composition of buffers used for DNA extraction, can inhibit the enzymes used in amplification (Monteiro et al., 1997; Schrader et al., 2012; Paulos et al., 2016). Therefore, the detection efficiency of the molecular test may have been influenced by the possible presence of inhibitory agents in the material (Ward and Wang, 2001), or the vegetable intake by the animals (Monteiro et al., 2001). There are differences in the performance of kits to extract DNA from oocysts depending on the pathogen, and the intensity of the infection (Paulos et al., 2016). The justification for the lower sensitivity of PCR is because the stool samples were used "in natura", without purification and in a small amount $(200 \mathrm{mg})$ when compared with TF-Test Coccidia, which was processed with $5.4 \mathrm{~g}$ of feces. It is noteworthy that, despite the comments above, the use of Nested-PCR in this study was extremely important, especially for the molecular confirmation of the parasite Cryptosporidium spp.

TF-Test Coccidia was considered an efficient technique and could be applied in the veterinary medicine field for the fecal diagnosis of Cryptosporidium spp. oocysts.

The preliminary results of this study allow us to move forward to the next research step: the interlaboratory validation of the TF-Test Coccidia technique. With this, we can begin with the study of computerized image analysis of Cryptosporidium spp. oocysts, which 
should result in advances in this type of diagnosis in public and private laboratory routines, as well as government programs.

\section{Conclusion}

In this study, we verified the effectiveness of the TF-Test Coccidia parasitological technique for the detection of Cryptosporidium spp. oocysts and observed a good concentration and morphology of the parasite, with a low amount of debris in the fecal smear.

\section{Acknowledgements}

We thank the Agência de Coordenação de Aperfeiçoamento de Pessoal de Nível Superior - CAPES, for granting Phd scholarship, São Paulo Research Foundation (FAPESP) for grant PIPE \#99/062284 and ImmunoCamp Science and Technology for research support, through investments in human resources and consumption material.

\section{References}

Center for disease control and prevention (CDC), 2015. Cryptosporidium: Diagnosis \& Detection, Retrieved from http://www.cdc.gov/parasites/crypto/ diagnosis.html (accessed 01.08.16.).

Carvalho, G.L.X., Moreira, L.E., Pena, J.L., Marinho, C.C., Bahia, M.T. Machado-Coelho, G.L.L., 2012. A comparative study of the TF-Test ${ }^{\circledR}$, Kato-Katz, Hoffman-Pons-Janer, Willis and Baermann-Moraes coprologic methods for the detection of human parasitosis. Mem. Inst. Oswaldo Cruz. 107, 80-84, http:// dx.doi.org/10.1590/S0074-02762012000100011.

Carvalho, J.B., Santos, B.M., Gomes, J.F., Suzuki, C.T.N., Hoshino Shimizu, S., Falcão, A.X., Pierucci, J.C., Matos, L.V.S., Bresciani, K.D.S., 2016. TF-Test modified: new diagnostic tool for human enteroparasitosis. J. Clin. Lab. Anal. 30, 293-300, http://dx.doi.org/10.1002/jcla.21854.

Coelho, W.M.D., Gomes, J.F., Amarante, A.F.T., Bresciani, K.D.S., Lumina, G., Hoshino-Shimizu, S., Leme, D.P., Falcão, A.X., 2013. A new laboratorial method for the diagnosis of gastrointestinal parasites in dogs. Rev. Bras. Parasitol. Vet. 22, 1-5, http://dx.doi.org/10.1590/S1984-29612013000100002.

Coelho, W.M.D., Gomes, J.F., Falcão, A.X., Santos, B.M., Soares, F.A., Suzuki, C.T.N. Amarante, A.F.T., Bresciani, K.D.S., 2015. Comparative study of five techniques for the diagnosis of canine gastrointestinal parasites. Rev. Bras. Parasitol. Vet. 24, 223-226, http://dx.doi.org/10.1590/S1984-29612015032.

Elliot, A., Morgan, U.M., Thompson, R.C.A., 1999. Improved staining method for detecting Cryptosporidium oocysts in stools using malachite green. J. Gen. Appl. Microbiol. 45, 139-142, http://dx.doi.org/10.2323/jgam.45.139.

Fayer, R., Santín, M., 2009. Cryptosporidium xiaoi n. sp. (Apicomplexa: Cryptosporidiidae) in sheep (Ovis aries). Vet. Parasitol. 164, 192-200, http://dx. doi.org/10.1016/j.vetpar.2009.05.011.

Fayer, R., Santín, M., Trout, J.M., 2008. Cryptosporidium ryanae n. sp. (Apicomplexa: Cryptosporidiidae) in cattle (Bos taurus). Vet. Parasitol. 156, 191-198, http:// dx.doi.org/10.1016/j.vetpar.2008.05.024.

Fayer, R., 2010. Taxonomy and species delimitation in Cryptosporidium. Exp. Parasitol. 124, 90-97, http://dx.doi.org/10.1016/j.exppara.2009.03.005.

Feng, Y., Ortega, Y., He, G., Das, P., Xu, M., Zhang, X., Fayer, R., Gatei, W., Cama, V., Xiao, L., 2007. Wide geographic distribution of Cryptosporidium bovis and the deer-like genotype in bovines. Vet. Parasitol. 144, 1-9, http://dx.doi.org/10. 1016/j.vetpar.2006.10.001.

Garcia, L.C., 2007. Diagnosis Medical Parasitology, 5. ed. A.S.M. Press, Washington.

Garcia, L.C., 2009. Practical Guide to Diagnostic Parasitology, 2. ed. A.S.M. Press, Washington, pp. 288-289.
Gomes, J.F., Hoshino-Shimizu, S., Dias, L.C.S., Araujo, A.J., Castilho, V.L.P., Neves, F.A.M.A., 2004. Evaluation of a novel kit (TF-Test) for the diagnosis of intestinal parasitic infections. J. Clin. Lab. Anal. 18, 132-138, http://dx.doi.org/10.1002/ jcla.20011.

Henriksen, S.A., Pohlenz, J.F., 1981. Staining of cryptosporidia by a modified Ziehl-Neelsen technique. Acta Vet. Scand. 22, 594-596.

Lennette, E.H., Balows, A., Hausler Junior, W.J., Shadomy, H.J., 1985. Manual of Clinical Microbiology, 4. ed. American Society of Microbiology, Washington, pp. 1149.

Lumina, G., Bricarello, P.A., Gomes, J.F., Amarante, A.F.T., 2006. Avaliação do kit TF-Test para o diagnóstico das infecções por parasitas gastrintestinais em ovinos. Braz. J. Vet. Res. Anim. Sci. 43, 496-501, http://dx.doi.org/10.1590/ S1413-95962006000400009.

Meloni, B.P., Thompson, R.C.A., 1996. Simplified methods for obtaining purified oocysts from mice and for growing Cryptosporidium parvum in vitro. J. Parasitol. 82, 757-762, http://dx.doi.org/10.2307/3283888.

Monteiro, L., Bonnemaison, D., Vekris, A., Petry, K.G., Bonnet, J., Vidal, R., Cabrita, J., Mégraud, F., 1997. Complex polysaccharides as PCR inhibitors in feces: Helicobacter pylori model. J. Clin. Microbiol. 35, 995-998.

Monteiro, L., Gras, N., Vidal, R., Cabrita, J., Mégraud, F., 2001. Detection of Helicobacter pylori DNA in human feces by PCR: DNA stability and removal of inhibitors. J. Microbiol. Methods 45, 89-94, http://dx.doi.org/10.1016/S01677012(01)00225-1.

Olson, M.E., O’Handley, R.M., Ralston, B.J., McAllister, T.A., Thompson, R.C.A., 2004. Update on Cryptosporidium and Giardia infections in cattle. Trends Parasitol. 20, 185-191, http://dx.doi.org/10.1016/j.pt.2004.01.015.

Paulos, S., Mateo, M., de Lucio, A., Hernández-de Mingo, M., Bailo, B., Saugar, J.M., Cardona, G.A., Fuentes, I., Mateo, M., Carmena, D., 2016. Evaluation of five commercial methods for the extraction and purification of DNA from human faecal samples for downstream molecular detection of the enteric protozoan parasites Cryptosporidium spp., Giardia duodenalis, and Entamoeba spp. J. Microbiol. Methods 127, 68-73, http://dx.doi.org/10.1016/j.mimet.2016.05. 020.

Rieux, A., Chartier, C., Pors, I., Delafosse, A., Paraud, C., 2013. Molecular characterization of Cryptosporidium isolates from high-excreting young dairy calves in dairy cattle herds in Western France. Parasitol. Res. 112, 3423-3431, http://dx.doi.org/10.1007/s00436-013-3520-2.

SAS Institute Inc, 2015. The SAS System, Release 9.3. SAS Institute Inc., Cary: NC.

Santín, M., Trout, J.M., Fayer, R., 2008. A longitudinal study of cryptosporidiosis in dairy cattle from birth to 2 years of age. Vet. Parasitol. 155, 15-23, http://dx. doi.org/10.1016/j.vetpar.2008.04.018.

Schrader, C., Schielke, A., Ellerbroek, L., Johne, R., 2012. PCR inhibitors occurrence, properties and removal. J. Appl. Microbiol. 113, 1014-1026, http:// dx.doi.org/10.1111/j.1365-2672.2012.05384.x.

Silverlås, C., de Verdier, K., Emanuelson, U., Mattsson, J.G., Björkman, C., 2010. Cryptosporidium infection in herds with and without calf diarrhoeal problems. Parasitol. Res. 107, 1435-1444, http://dx.doi.org/10.1007/s00436-010-2020-x.

Teixeira, W.F.P., Coelho, W.M.D., Soutello, R.V.G., Oliveira, F.P., Homem, C.G., Nunes, C.M., Meireles, M.V., 2011. Diagnóstico de criptosporidiose em amostras fecais de bezerros por imunofluorescência direta e microscopia de contraste de fase. Cienc. Rural. 41, 1057-1062.

Vargas Jr., S.F., Marcolongo-Pereira, C., Adrien, M.L., Fiss, L., Molarinho, K.R., Soares, M.P., Schild, A.L., Sallis, E.S.V., 2014. Surto de criptosporidiose em bezerros no Sul do Rio Grande do Sul. Pesq. Vet. Bras. 34, 749-752.

Ward, L.A., Wang, Y., 2001. Rapid methods to isolate Cryptosporidium DNA from frozen feces for PCR. Diagn. Microbiol. Infect. Dis. 41, 37-42, http://dx.doi.org/ 10.1016/S0732-8893(01)00276-0.

Xiao, L., Alderisio, K., Limor, J., Royer, M., Lal, A.A., 2000. Identification of species and sources of Cryptosporidium oocysts in storm waters with a small-subunit rRNA-based diagnostic and genotyping tool. Appl. Environ. Microbiol. 66, 5492-5498, http://dx.doi.org/10.1128/AEM.66.12.5492-5498.2000.

Xiao, L., 2010. Molecular epidemiology of cryptosporidiosis: an update. Exp. Parasitol. 124, 80-89, http://dx.doi.org/10.1016/j.exppara.2009.03.018. 